\title{
Neuroendocrine tumors producing calcitonin: characteristics, prognosis and potential interest of calcitonin monitoring during follow-up
}

\author{
Cécile Nozières ${ }^{1,4}$, Laurence Chardon ${ }^{2}$, Bernard Goichot ${ }^{3}$, \\ Françoise Borson-Chazot ${ }^{4,8}$, Valérie Hervieu ${ }^{5,7,8}$, Karim Chikh ${ }^{6,8}$, \\ Catherine Lombard-Bohas ${ }^{1}$ and Thomas Walter ${ }^{1,7,8}$
}

'Pavillon E, UJOMM, Hospices Civils de Lyon, Hôpital Edouard Herriot, Service d'Oncologie Médicale, 69437 Lyon Cedex 03, France, ${ }^{2}$ Hospices Civils de Lyon, Hôpital Edouard Herriot, Service de Biochimie et Biologie Moléculaire, 69437 Lyon Cedex 03, France, ${ }^{3}$ Hôpitaux Universitaires de Strasbourg, Service de Médecine Interne, Endocrinologie et Nutrition, Hôpital de Hautepierre, Avenue Molière, 67098 Strasbourg Cedex, France, ${ }^{4}$ Hospices Civils de Lyon, Fédération d'Endocrinologie du Pôle Est, Aile A1, 59 Boulevard Pinel, 69500 Bron, France, ${ }^{5}$ Hospices Civils de Lyon, Hôpital Edouard Herriot, Service Central d'Anatomie et Cytologie Pathologiques, 69437 Lyon Cedex 03, France, ${ }^{6}$ Hospices Civils de Lyon, Centre Hospitalier Lyon Sud, Centre de Biologie, 69495 Pierre-Bénite, France, ${ }^{7}$ INSERM, UMR 1052, Lyon Cancer Research Center, Faculté Laennec, 69372 Lyon Cedex 08, France and ${ }^{8}$ Université de Lyon, Université Claude Bernard Lyon 1, 69622 Villeurbanne Cedex, France

\author{
Correspondence \\ should be addressed \\ to T Walter \\ Email \\ thomas.walter@chu-lyon.fr
}

\begin{abstract}
Objectives: Inappropriate calcitonin (CT) release, a major feature of medullary thyroid cancer (MTC), may occur in neuroendocrine tumors (NETs). The aims of this retrospective study were to assess $i$ ) the characteristics and prognosis of CT-producing NETs, and ii) the value of CT monitoring during follow-up.

Methods: All patients with NETs in whom serum CT was assayed between 2010 and 2012 were included. MTCs were excluded. Clinical, biological, and histological characteristics were studied.

Results: Twenty-one (12\%) of 176 patients in whom serum CT was systematically assayed had concentrations $>100 \mathrm{ng} / \mathrm{l}$, with tumours predominantly of bronchial or pancreatic origin $(P<0.0001)$, and of high grade $(P=0.0006)$. Poor prognosis was linked to high CT levels, poor differentiation, and grade 3. In a total group of 24 patients with serum CT $>100 \mathrm{ng} / \mathrm{l}$, symptoms potentially attributable to CT were recorded in eight, with occasional overlap with the carcinoid syndrome among other secretory syndromes. Immunohistochemistry could be performed in six tumor specimens, CT being detected in five.

In 11 patients with five or more successive CT assays, hormone levels were fairly well correlated with clinical courses. Conclusion: Serum CT levels may be raised in some patients with NETs, especially from foregut origin, and of high grade. The suggested value of CT monitoring during follow-up must be confirmed in further studies.
\end{abstract}

\section{Introduction}

Neuroendocrine tumors (NETs) often express one, and sometimes several, peptide(s) or amine(s), among which insulin, gastrin, and serotonin are the most frequently encountered. Inappropriate secretion may result in a secretory syndrome that triggers peptide or amine assays, then the search for the tumoral source and its diagnosis at pathology.

Calcitonin (CT) is one of the two products of the gene Calc-1 which codes for two proteins: procalcitonin (PCT)
(C) 2016 European Society of Endocrinology Printed in Great Britain and calcitonin gene relate-peptide (CGRP). PCT is mainly expressed in thyroid C cells and CGRP in neuronal cells. In C cells, PCT is subsequently cleaved by a convertase enzyme to generate CT. PCT is usually not secreted in the blood but may be released during bacterial infections and has become an interesting marker in that situation (1). $\mathrm{C}$ cells are present not only in the thyroid gland but also in parathyroid glands, thymus, lungs, small intestine, liver 
and bladder. Mature CT is the marker of medullary thyroid cancer (MTC) but may be occasionally secreted by other tumoral cells. In fact, hypercalcitoninemia is not pathognomonic of MTC (2), and drugs, renal insufficiency, hyperparathyroidism or NETs could raise CT serum levels. However, CT-secreting NETs are rare, with few reports in the literature $(3,4,5,6,7,8,9,10,11)$. A series of six cases of pancreatic origin showed that the tumors were often malignant, and that half the patients suffered from diarrhea (3). Another study reported that GEP-NETs with high CT had a worse prognosis than NETs with normal CT levels (9). Additional evaluation of CT-producing NETs may improve our understanding of the significance and interest of that inappropriate secretion.

Therefore, we studied 176 NETs with at least one determination of CT in order to explore: i) the clinical and histological characteristics of NETs with high CT in comparison with other NETs, and ii) the prognostic value of the marker. Then, we focused on a series of 24 patients with high CT to assess the clinical profile, the response to somatostatin analogs, and the potential input for follow-up.

\section{Subjects and methods}

\section{Patients}

All consecutive patients from gastroenterology and oncology departments of our ENETs center with at least one blood sample for CT measurement between January 2010 and September 2012 were retrieved from the biochemistry laboratory data base. Among 295 patients with 713 calcitonin determinations, we found two patients with a MTC who were excluded from the study. The 293 remaining patients were matched with the list of 994 patients with NETs from our institutional data base, yielding a series of 176 patients with NETs in whom CT was assayed at least once. The NETs were diagnosed, classified, and graded according to ENETS recommendations (12). Then these 21 patients and three additional cases with similar work-up from a collaborating center were studied as to the clinicobiological profile associated to high serum CT levels.

\section{Serum biomarkers}

All samples were collected on the morning after an overnight fast. Serum CT was assayed using an immunoradiometric assay (IRMA-HCT, Cisbio Bioassays, Saclay, France; reference range $(n)<10 \mathrm{ng} / \mathrm{l})$. High CT was here defined as above $100 \mathrm{ng} / \mathrm{lin}$ order to avoid false positive values. When a patient had high CT level(s) during the study period, previous serum samples were analyzed if available. Measurement of serum chromogranin A $(\mathrm{CgA})$ levels was performed with a commercially available solid-phase two-site IRMA using $\mathrm{MAB}$ directed against the central domain of the protein (145-245) and human recombinant $\mathrm{CgA}$ as standard (CgA-Riact kit, Cisbio Bioassays, reference range $<98 \mu \mathrm{g} / \mathrm{l}$ ).

\section{Patients with high CT levels and follow-up study}

Twenty-four patients were included in this phase of the study. Histological and immunohistological findings were based on the surgical resection specimen $(n=13)$ or on the biopsy of metastases $(n=11)$. Calcitonin immunostaining was assessed when a pathological specimen was still available (clone A576, Dako, Glostrup, Denmark). Clinical courses and treatments of these 24 patients were studied with clinical, biological and morphological assessment. When tumors were functional, clinical response to therapy was defined as a $>50 \%$ decrease in number of stools.

\section{Statistical analysis}

Categorical variables were expressed as percentages, and compared by the $\chi^{2}$-test or with Fisher's exact test when appropriate. Continuous variables were expressed as median with range and were compared by the MannWhitney test. Overall survival (OS) was calculated from the diagnosis to the date of death or last follow-up. OS was assessed using Kaplan-Meier analysis and comparisons were performed using the log-rank test. For continuous variables, the cut-off level chosen was their median value. A $P$ value of $<0.05$ was considered statistically significant. Cox proportional hazard models were developed using relevant clinico-pathologic variables to determine the association of each parameter with OS. Only variables with a $P$ value of $<0.10$ at univariate analysis were introduced in the Cox model. Relative risks were expressed as hazard ratios (HRs) with 95\% confidence intervals (CIs). The cut-off date for the final analysis was July 1, 2014. All statistical analyses were performed using Statistical Package for Social Sciences version 17.0.

\section{Results}

\section{Reference-center population: characteristics and prognosis}

The characteristics of the 176 patients with NETs in whom CT was assayed once or more are given in Table 1 . 
Table 1 General features of patients according to serum calcitonin (CT) levels. Data are presented as $n(\%)$.

\begin{tabular}{|c|c|c|c|c|}
\hline Characteristics & $\begin{array}{c}\text { Patients } \\
\text { with high } \\
\text { CT, } n=21\end{array}$ & $\begin{array}{l}\text { Patients } \\
\text { with low } \\
\text { CT, } n=155\end{array}$ & $\begin{array}{c}\text { All } \\
\text { patients, } \\
n=176\end{array}$ & $P$ value \\
\hline Male & $12(57 \%)$ & $86(55 \%)$ & $98(56 \%)$ & 0.89 \\
\hline $\begin{array}{l}\text { Age, median } \\
\text { (range) }\end{array}$ & $52(37-86)$ & $56(15-88)$ & $56(15-88)$ & 0.19 \\
\hline $\begin{array}{l}\text { Primary tumour } \\
\text { localization }\end{array}$ & & & & $<0.0001$ \\
\hline Pancreas & $10(48 \%)$ & $41(26 \%)$ & $51(29 \%)$ & \\
\hline Lung & $9(43 \%)$ & $8(5 \%)$ & $17(10 \%)$ & \\
\hline $\begin{array}{l}\text { Gastrointestinal } \\
\text { tract }\end{array}$ & $2(9 \%)$ & $94(61 \%)$ & $96(54 \%)$ & \\
\hline Other & $0(0 \%)$ & $5(3 \%)$ & $5(3 \%)$ & \\
\hline Unknown & $0(0 \%)$ & $7(5 \%)$ & $7(4 \%)$ & \\
\hline $\begin{array}{l}\text { Functioning } \\
\text { tumors other } \\
\text { than CT }\end{array}$ & $9(43 \%)$ & $42(27 \%)$ & $51(29 \%)$ & 0.13 \\
\hline Differentiation & & & & 0.41 \\
\hline $\begin{array}{l}\text { Well- } \\
\text { differentiated }\end{array}$ & $19(90 \%)$ & $131(95 \%)$ & $150(94 \%)$ & \\
\hline $\begin{array}{l}\text { Poorly- } \\
\text { differentiated }\end{array}$ & $2(10 \%)$ & $7(5 \%)$ & $9(6 \%)$ & \\
\hline Grading & & & & 0.006 \\
\hline Grade 1 & $2(10 \%)$ & $24(33 \%)$ & $26(28 \%)$ & \\
\hline Grade 2 & $10(53 \%)$ & $42(58 \%)$ & $52(57 \%)$ & \\
\hline Grade 3 & $7(37 \%)$ & $7(10 \%)$ & $14(15 \%)$ & \\
\hline Non available & 2 & 82 & 84 & \\
\hline $\begin{array}{l}\text { Metastatic } \\
\text { disease }\end{array}$ & $21(100 \%)$ & $141(91 \%)$ & $162(92 \%)$ & 0.15 \\
\hline
\end{tabular}

The distribution of serum CT and CgA levels are given in Fig. 1a. Median serum levels of CT was 2 (1.5-15 087) ng/l. CT levels were normal $(<10 \mathrm{ng} / \mathrm{l})$ in $144(82 \%)$ patients, between 10 and $30 \mathrm{ng} / \mathrm{l}$ in 9 (5\%), between 30 and $100 \mathrm{ng} / \mathrm{l}$ in $2(1 \%)$ patients, and above $100 \mathrm{ng} / \mathrm{l}$ in 21 (12\%) patients. There was no significant correlation (Pearson test: $P=0.19$ ) between serum CT and serum CgA concentrations (Fig. 1b). High CT levels (>100 ng/l) were significantly associated with pancreatic or lung NETs, and high grade tumors (Table 1).

The median follow-up of the 176 patients was 5.6 (0.1-27.7) years from diagnosis. The median OS from diagnosis was 13.2 years for the whole population: 5.1 (1.8-8.4) years for patients with high CT whereas it was not reached for patients with low CT $(P<0.0001)$. Prognosis factors are shown in Table 2 . Low grade, gastrointestinal NETs and low CT were associated with better survival after univariate analysis. However, only the G3 grade remained significantly associated with poor survival after multivariate analysis. High CT concentration failed to reach significance as a factor of poorer prognosis $(\mathrm{HR}=0.4(0.2-1.1), P=0.07)$ (Fig. 2).

\section{Characteristics of the $\mathbf{2 4}$ patients with high CT}

In the 24 patients with serum CT above $100 \mathrm{ng} / \mathrm{l}$, another etiology of high CT (such as MTC) was excluded from clinical and ultrasound data within a median follow-up of $31(2-171)$ months. Tumor specimens from six patients were available for $\mathrm{CT}$ immunohistochemical staining. One tumor was negative for CT, two NETs had heterogeneous strong staining, and three had homogeneous strong staining (Fig. 3).

Of these 24 patients with NETs, 20 had synchronous high CT whereas high CT occurred 7, 9, 35, and 36 months after diagnosis in the four other patients, respectively. Most patients had NETs from pancreas (48\%) or lung (43\%). One patient had a NET from the stomach and one from appendix. Fourteen of the 24 (58\%) patients
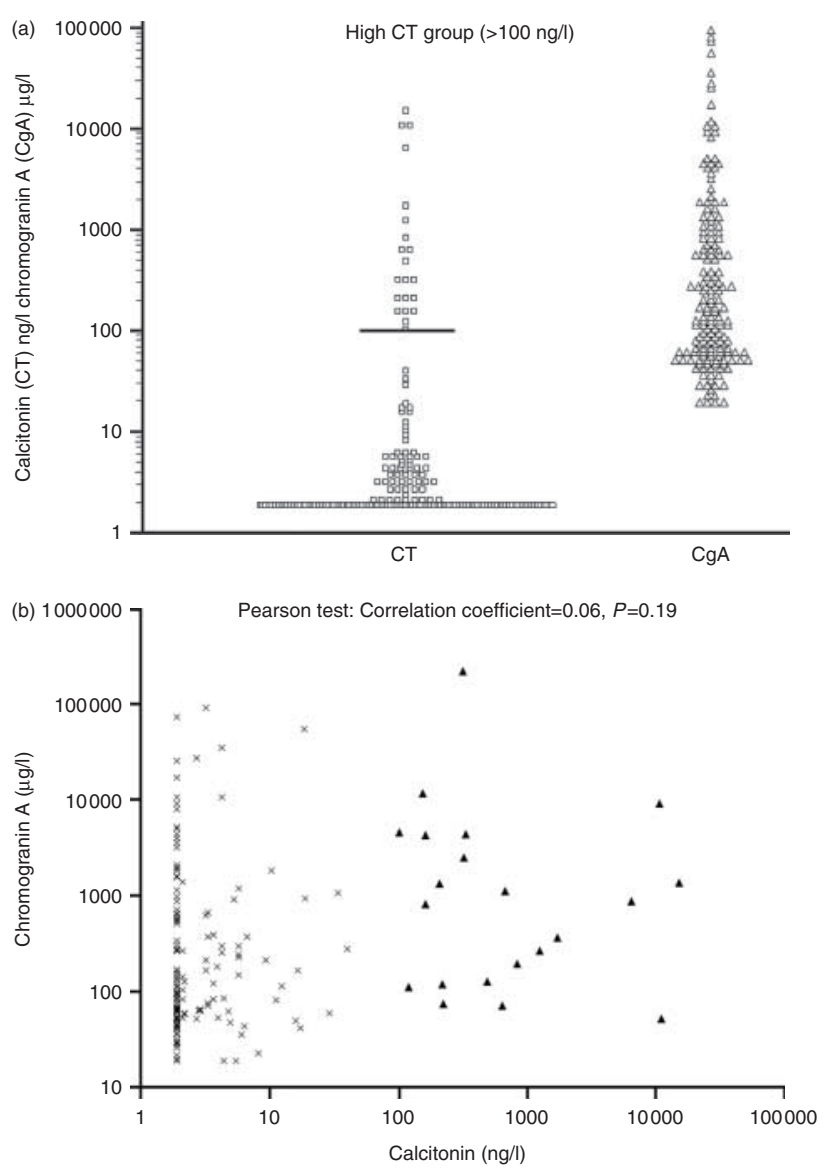

\section{Figure 1}

Individual serum calcitonin ( $\mathrm{CT}, \mathrm{ng} / \mathrm{l})$ and chromogranin $\mathrm{A}$ $(\mathrm{CgA}, \mu \mathrm{g} / \mathrm{l})$ levels (a), and the lack of correlation (low correlation coefficient with $r=0.06$ and $P=0.19$, obtained by Pearson's analysis) between serum CT (ng/l) and CgA ( $\mu \mathrm{g} / \mathrm{l})$ levels (b), in the whole population of patients with NETs $(n=176)$. 
Table 2 Univariate and multivariate Cox regression analysis of the prognosis factors in 176 patients with neuroendocrine tumors.

\begin{tabular}{|c|c|}
\hline Parameters & $\begin{array}{c}\text { P value, univariate } \\
\text { analysis }\end{array}$ \\
\hline Sex, male vs female & 0.76 \\
\hline Age, $>55$ vs $<55$ years & 0.95 \\
\hline Primary tumour location (GI vs $\mathrm{P}$ vs $\mathrm{L}$ ) & 0.006 \\
\hline Distant metastases, yes vs no & 0.28 \\
\hline Functioning tumor, yes vs no & 0.41 \\
\hline Elevated calcitonin, no vs yes & $<0.0001$ \\
\hline Differentiation, poorly vs well & 0.03 \\
\hline Grade, 1 vs 2 vs 3 & $<0.0001$ \\
\hline
\end{tabular}

\begin{tabular}{|c|c|}
\hline Risk ratio $(95 \% \mathrm{Cl})$ & $\begin{array}{c}\text { P value }{ }^{\text {a }} \text {, multivariate } \\
\text { analysis }\end{array}$ \\
\hline - & - \\
\hline- & - \\
\hline GI v P, $0.8(0.3-2.6)$ & 0.64 \\
\hline $\mathrm{Gl} v \mathrm{~L}, 0.7(0.2-2.7)$ & 0.77 \\
\hline- & - \\
\hline- & - \\
\hline $0.4(0.2-1.1)$ & 0.07 \\
\hline $2.2(0.5-9.6)$ & 0.31 \\
\hline G1 v G3, $0.06(0.02-0.2)$ & $<0.0001$ \\
\hline G2 v G3, $0.1(0.03-0.4)$ & 0.001 \\
\hline
\end{tabular}

$L$, lung; $\mathrm{Gl}$, gastrointestinal; $P$, pancreas.

aariables with $P<0.1$ at univariate analysis were retained for multivariate logistic regression analysis.

underwent a resection of their primary tumor. Patients were treated with a median of 2 (1-6) lines of antitumoral treatment. Median age was 54 (37-83) years and 57\% were male. No patient had MEN1 syndrome. Ninety percent of NETs were well-differentiated. Most of them were highgrade tumors: 10, 53, and 37\% were G1, G2, and G3 respectively (Table 1). All patients had synchronous metastases, with a median of 2 (1-4) metastatic sites, mostly in the liver or bones. CT levels tended to be higher in poorly differentiated tumors (median of 658 (333-10 702) ng/l than in well differentiated NETs (224 (102-15 087) ng/l, $P=0.3$ ), and in high than in low-grade NETs (82 (104-254) ng/l) for G1, 224 (163-15 087) ng/l for G2, and 677 (208-10 702) ng/l for G3, $P=0.2$ ), but not with the number of metastatic sites $(P=0.9)$.

Of these 24 patients, eight (33\%) presented with diarrhea, fatigue, and weight loss, which might be related to high CT levels. Somatostatin analogs were used for diarrhea in five cases with clinical response for two of them. Eight patients had other secretory syndromes, respectively qualified as six carcinoid syndromes, one VIPoma syndrome, and one Cushing's syndrome. Four patients also had hypercalcemia $(>3 \mathrm{mmol} / \mathrm{l})$ related to PTHrp and six other patients with bone metastases had hypercalcemia between 2.5 and $3.0 \mathrm{mmol} / \mathrm{l}$.

\section{Follow-up study}

Eleven patients had more than five serum CT determinations: seven pancreatic NETs and four lung carcinoids. Evolutions of serum CgA and CT levels in four illustrative cases are presented in Fig. 4. Two of them were previously published: one woman with lung carcinoid tumor presenting with a Cushing's syndrome during her follow-up (Fig. 4c) (13) and one man with pancreatic NET who received six lines of antitumoral treatment (Fig. 4d) (14). Eight of the 11 patients had their highest CT concentration just before death (Fig. $4 a$, b, and d). The CgA and CT changes along time were similar in $3 / 11$ patients (Fig. 4 b). Some patients had CT change without change in CgA levels (Fig. 4a, c, and d). In patient no. c, CT levels decreased with the use of somatostatin analog (Fig. 4c).

\section{Discussion}

We here report the largest series, so far, of NETs with inappropriate CT secretion. In our NET population (43\%

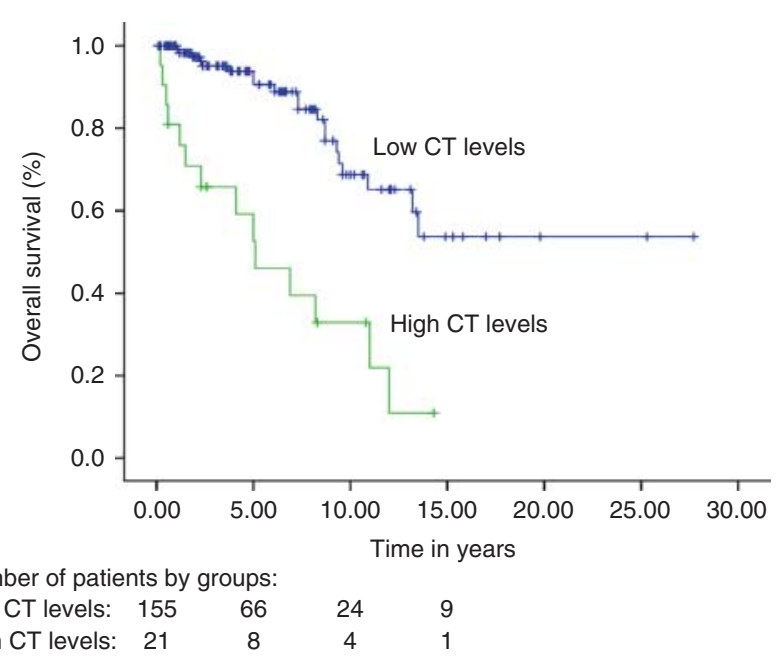

Figure 2

Overall survival according to the presence or absence of high serum calcitonin levels. 


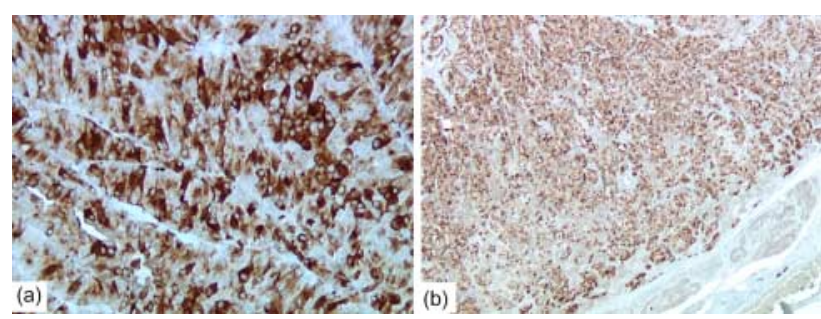

Figure 3

Strong immunostaining for calcitonin protein of tumor cells in a liver metastasis of pancreatic NET (a), and in a pancreatic primary tumor (b). Original magnifications: $a, \times 20 ; b, \times 4$. A full colour version of this figure is available at http://dx.doi.org/10.1530/EJE-15-0917.

of foregut NETs), 21 (12\%) of 176 patients had serum CT concentrations $>100 \mathrm{ng} / \mathrm{l}$, which is in accordance with other studies: five (16\%) of 32 foregut NETs in the Wuilmet's study (9) and six (9\%) of 66 pancreatic NETs in the Fleury's study (3). However, this frequency depends: i) on the cut-off used to define 'high CT' (100 ng/l in our study, $20 \mathrm{ng} / \mathrm{l}$ in the Fleury study and $10 \mathrm{ng} / \mathrm{l}$ in the Wuilmet study), and ii) on the NET populations (NETs from various primaries in our study, whereas Wuilmet et al. (9) included only foregut NETs and Fleury et al. (3) included only pancreatic NETs).

We show that high CT levels are predominantly met in NETs from foregut origin (pancreas and lung) and with high grades. In the present group, no patient with midgut carcinoid (except one from appendix) had a raised CT concentration. Therefore, it seems not useful to assay CT in patients with small-bowel NETs even in a context of diarrhea without flushing. In contrast, patients with foregut NETs and unexplained diarrhea at diagnosis may be tested for CT secretion, including during follow-up as four of our 21 patients had metachronous secretion of CT. Some case reports $(4,5,6,7,8)$ described that patients with high-CT NETs are often associated with secretory syndrome, especially somatostatinoma. We could not demonstrate this point in our study even if a trend exists; $43 \%$ of high-CT patients had functioning NETs compared with $27 \%$ in low-CT cases $(P=0.13)$. However, in most case reports, authors defined as functioning tumor any NET with positive immunochemical tissue staining, what introduces a strong bias. In high-CT patients, no other etiology of high-CT was found. We chose CT levels above $100 \mathrm{ng} / \mathrm{l}$, in order to limit false positive values. Ten patients had hypercalcemia (bone metastasis or PTHrp), which is known to sometimes increase CT, but
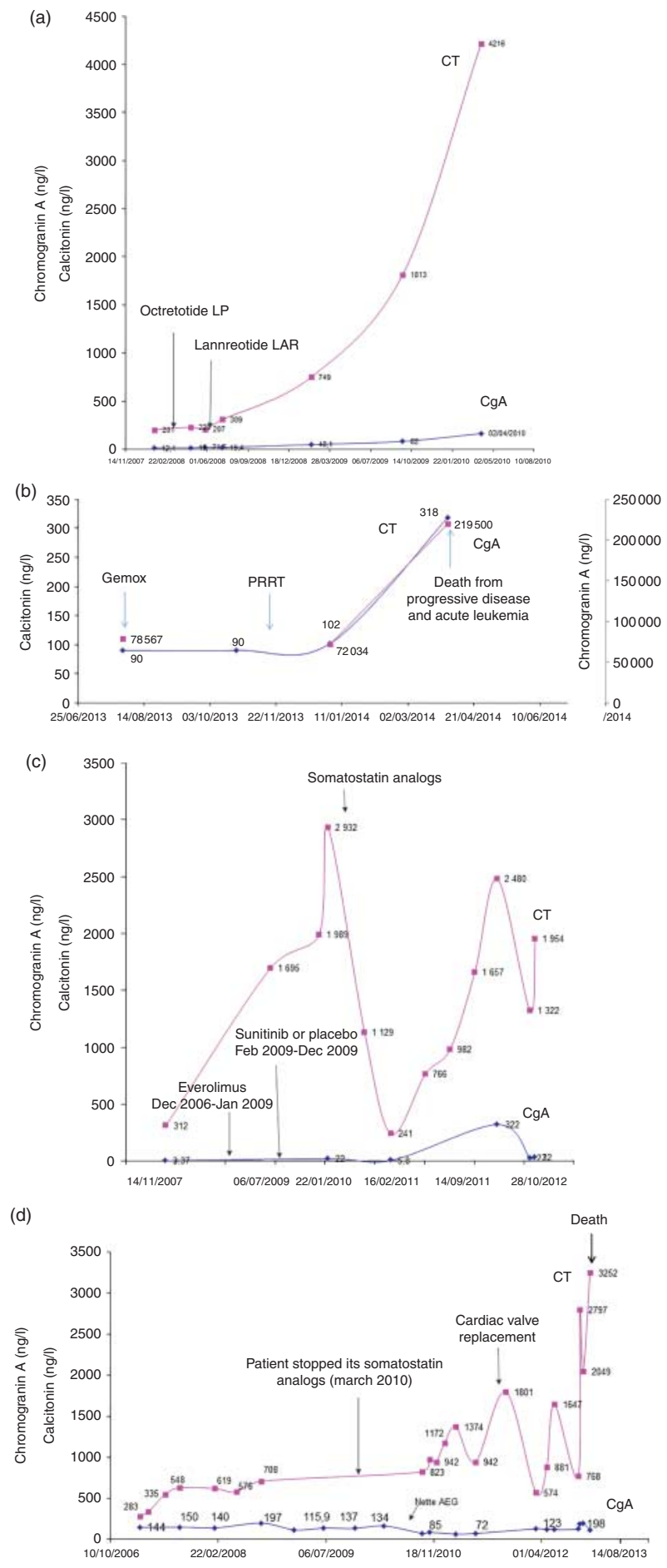

\section{Figure 4}

Representative examples of the evolution of serum chromogranin A ( $\mathrm{CgA}$ ) and calcitonin (CT) levels in four patients with NETs from lung ( $a, b$, and $c$ ) or pancreas (d). More data on medical history of patients ' $c$ ' (13) and ' $d$ ' (14) are available in previous publications. A full colour version of this figure is available at http://dx.doi.org/10.1530/EJE-15-0917. 
usually not over $>100 \mathrm{ng} / \mathrm{l}(15,16)$. Therefore, very high serum CT levels should also evoke lung or pancreatic NETs, if no thyroid tumor is detected at palpation and ultrasonography.

In our patients with NETs, there was a trend towards poor survival in case of high CT, but this was not significant after multivariate analysis (Fig. 2 and Table 2). The trend is consistent with others studies. Wuilmet et al. (9) reported that five of 32 patients with NETs and CT $>10 \mathrm{ng} / \mathrm{l}$ were associated with poor prognosis. However, no multivariate analysis was performed in this small study and these five patients had a NET more often with poor differentiation, a high Ki67 and liver metastases, three well-known poor prognostic factors in NETs. We also found these confounding factors in our study, since higher CT levels tended to be associated with poorly differentiated and high-grade tumors.

It is difficult to retrospectively report the percentage of patients with symptoms (diarrhea) related to CT and not due to any other etiology. Eight of the 24 (33\%) patients with high CT had diarrhea in our study, but six of them also had the carcinoid syndrome. Most of these patients had poor or partial response to somatostatin analogs which is common with diarrhea related to high-CT in MTC, in comparison with diarrhea due to serotonin (carcinoid syndrome) (17). In the literature, there is a publication bias as most case reports are on patients with symptoms. However, in the two series of NETs patients with CT determination, including five and six patients with tumors secreting CT, only one (20\%) and three $(50 \%)$ had symptoms attributed to the peptide (diarrhea) $(3,9)$. This is concordant with the fact that, in MTC, symptoms only occur in advanced metastatic forms with very high CT levels (18). Finally, we were able to describe the follow-up of CT and CgA levels in 11 patients. CT changes seem to be poorly correlated to CgA changes, but the highest CT levels in a given patient are often recorded shortly before death. The usefulness of CT follow-up must be better demonstrated in further studies.

Our study, by its retrospective nature, has some limitations. However, most data collected was extracted from our database, prospectively accrued, except that of the follow-up study. Therefore, the potential interest of calcitonin monitoring during follow-up has to be interpreted with caution: i) we did not systematically use RECIST criteria in follow-up of the 24 patients with high $\mathrm{CT}$; ii) CT determinations were not systematically performed at each morphological follow-up in order to better assess the correlation between CT and tumor burden changes; iii) daily numbers of stools were not systematically reported in patients charts so as to confirm that symptoms changes were related to variations of CT.

In conclusion, $12 \%$ of the 176 NET patients had CT $>100 \mathrm{ng} / \mathrm{l}$, but only one third had symptoms potentially related to this peptide. Diarrhea associated with high CT usually did not respond to somatostatin analogs. After exclusion of MTC, high CT levels should evoke a NET especially from foregut location. High CT levels in NETs are associated with high-grade tumors. Further studies are needed to ascertain the potential link between CT changes and clinical course in patients with NETs.

\section{Declaration of interest}

The authors declare that there is no conflict of interest that could be perceived as prejudicing the impartiality of the research reported.

\section{Funding}

This research did not receive any specific grant from any funding agency in the public, commercial or not-for-profit sector.

\section{Author contribution statement}

Study design: C Nozières, L Chardon, T Walter; collection of data: C Nozières, L Chardon, B Goichot, V Hervieu, K Chikh, T Walter; writing the manuscript: C Nozières, L Chardon, T Walter; approval of the manuscript: all authors.

\section{References}

1 Matwiyoff GN, Prahl JD, Miller RJ, Carmichael JJ, Amundson DE, Seda G $\&$ Daheshia M. Immune regulation of procalcitonin: a biomarker and mediator of infection. Inflammation Research 201261 401-409. (doi:10.1007/s00011-012-0439-5)

2 Toledo SP, Lourenco DM Jr, Santos MA, Tavares MR, Toledo RA \& Correia-Deur JE. Hypercalcitoninemia is not pathognomonic of medullary thyroid carcinoma. Clinics (Sao Paulo) 200964 699-706. (doi:10.1590/S1807-59322009000700015)

3 Fleury A, Flejou JF, Sauvanet A, Molas G, Vissuzaine C, Hammel P, Levy P, Belghiti J, Bernades P \& Ruszniewski P. Calcitonin-secreting tumors of the pancreas: about six cases. Pancreas 199816 545-550. (doi:10.1097/00006676-199805000-00014)

4 Do Cao C, Mekinian A, Ladsous M, Aubert S, D’Herbomez M, Pattou F, Bourdelle-Hego MF \& Wemeau JL. Hypercalcitonemia revealing a somatostatinoma. Annales D'endocrinologie 201071 553-557. (doi:10.1016/j.ando.2010.05.001)

5 Pratz KW, Ma C, Aubry MC, Vrtiska TJ \& Erlichman C. Large cell carcinoma with calcitonin and vasoactive intestinal polypeptideassociated Verner-Morrison syndrome. Mayo Clinic Proceedings 200580 116-120. (doi:10.1016/S0025-6196(11)62968-6)

6 Sugimoto F, Sekiya T, Saito M, Iiai T, Suda K, Nozawa A, Nakazawa T, Ishizaki T \& Ikarashi T. Calcitonin-producing pancreatic somatostatinoma: report of a case. Surgery Today 199828 1279-1282. (doi:10.1007/ BF02482815)

7 Galmiche JP, Colin R, DuBois PM, Chayvialle JA, Descos F, Paulin C \& Geffroy Y. Calcitonin secretion by a pancreatic somatostatinoma. New England Journal of Medicine 19782991252. 
8 Asa SL, Kovacs K, Killinger DW, Marcon N \& Platts M. Pancreatic islet cell carcinoma producing gastrin, $\mathrm{ACTH}$, alpha-endorphin, somatostatin and calcitonin. American Journal of Gastroenterology 1980 74 30-35.

9 Wuilmet L, Jovenin N, Larbre H, Levy-Bohbot N, Diebold MD, Jolly D, Delemer B, Thiefin G \& Cadiot G. Digestive calcitonin-secreting tumors of the foregut: comparison with non-calcitonin-secreting tumors. European Journal of Gastroenterology \& Hepatology 200618 951-955. (doi:10.1097/01.meg.0000230091.76168.f9)

10 Kon T, Wada R, Suzuki R, Nakayama Y, Ebina Y \& Yagihashi S. VIP and calcitonin-producing pancreatic neuroendocrine tumor with watery diarrhea: clinicopathological features and the effect of somatostatin analogue. Journal of the Pancreas 201213 226-230.

11 Schneider R, Waldmann J, Swaid Z, Ramaswamy A, Fendrich V, Bartsch DK \& Schlosser K. Calcitonin-secreting pancreatic endocrine tumors: systematic analysis of a rare tumor entity. Pancreas 201140 213-221. (doi:10.1097/MPA.0b013e3182015f5d)

12 Rindi G, Kloppel G, Alhman H, Caplin M, Couvelard A, de Herder WW, Erikssson B, Falchetti A, Falconi M, Komminoth P et al. TNM staging of foregut (neuro)endocrine tumors: a consensus proposal including a grading system. Virchows Archiv 2006449 395-401. (doi:10.1007/ s00428-006-0250-1)

13 Cassier PA, Abou-Amara-Olivieri S, Artru P, Lapalus MG, Riou JP \& Lombard-Bohas C. Mifepristone for ectopic ACTH secretion in metastatic endocrine carcinomas: report of two cases. European Journal of Endocrinology 2008158 935-938. (doi:10.1530/ EJE-07-0792)

14 Walter T, Scoazec JY, Couderc C, Forestier J, Roche C, Chayvialle JA \& Lombard-Bohas C. Well-differentiated pancreatic islet cell carcinoma: is there reversibility in mTOR inhibitor resistance? Acta Oncologica 2011 50 731-732. (doi:10.3109/0284186X.2011.562919)

15 Levy-Bohbot N, Patey M, Larbre H, Hecart AC, Caron J \& Delemer B. How to interprete hypercalcitoninemia? La Revue de Médecine Interne 200627 610-615.

16 Conte-Devolx B, Morlet-Barla N, Roux F, Sebag F, Henry JF \& Niccoli P. Could primary hyperparathyroidism-related hypercalcemia induce hypercalcitoninemia? Hormone Research in Poediatrics 201073 372-375.

17 Vainas I, Koussis C, Pazaitou-Panayiotou K, Drimonitis A, Chrisoulidou A, Iakovou I, Boudina M, Kaprara A \& Maladaki A. Somatostatin receptor expression in vivo and response to somatostatin analog therapy with or without other antineoplastic treatments in advanced medullary thyroid carcinoma. Journal of Experimental \& Clinical Cancer Research 200423 549-559.

18 Wells SA, Asa SL, Dralle H, Elisei R, Evans DB, Gagel RF, Lee N, Machens A, Moley JF, Pacini F et al. Revised American Thyroid Association guidelines for the management of medullary thyroid carcinoma. Thyroid 201525 567-610. (doi:10.1089/thy.2014.0335)

Received 14 September 2015

Revised version received 26 November 2015

Accepted 15 December 2015 